\title{
Circulating Hormone Levels in Hatchlings of Green Turtle, Chelonia mydas, from Ras Al-Hadd Reserve, Oman
}

\author{
A. Y. A. AlKindi \\ Department of Biology, College of Science, Sultan Qaboos University, \\ P.O. Box 36, Al-Khod 123, Sultanate of Oman, \\ Email:aakindy@squ.edu.om
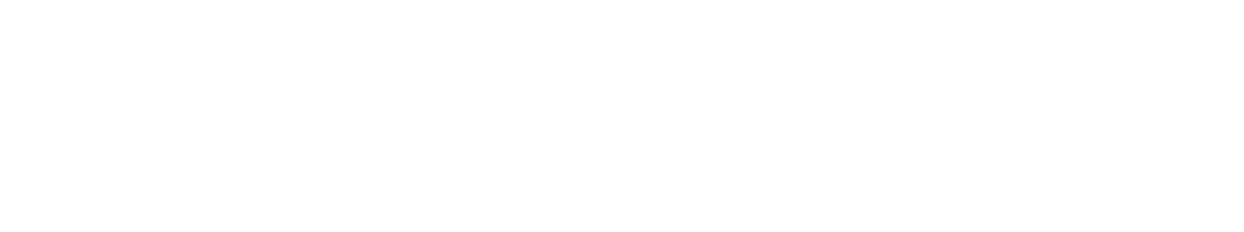

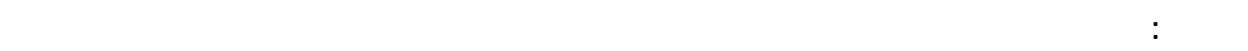

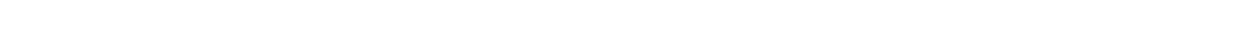

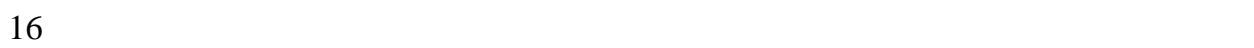

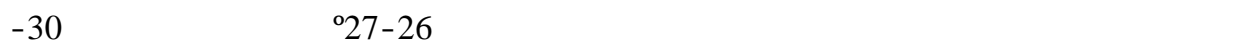

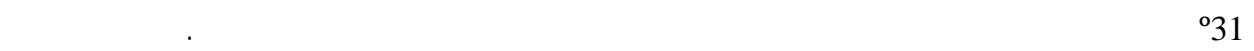

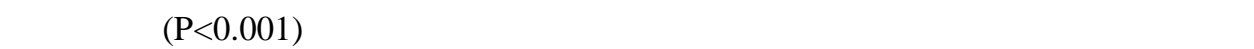

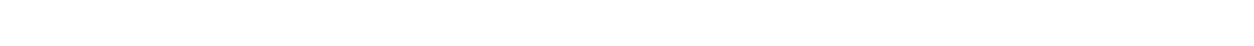

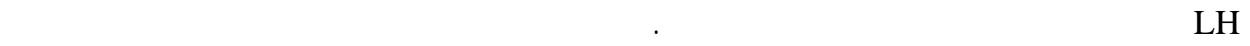

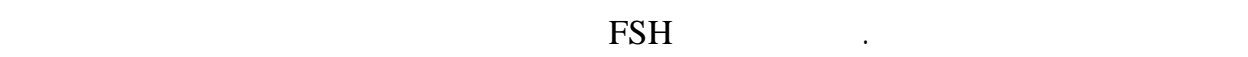
هذه النتائج وأهميتها في هذا البحث.

ABSTRACT: Post-hatching levels of plasma estradiol $\left(E_{2}\right)$, Progesterone (Pro), testosterone (T), Luteinizing Hormone (LH), Follicle-Stimulating Hormone (FSH) and thyroxine $\left(\mathrm{T}_{4}\right)$ were monitored in hatchlings of Green Turtle, Chelonia mydas immediately after emergence. Eggs were collected at random from 5 nests. The eggs were placed in incubators $16 \mathrm{hr}$ after oviposition set at $26-27^{\circ} \mathrm{C}$ for male producing hatchlings and at $30-31^{\circ} \mathrm{C}$ for female producing hatchlings. Blood was collected after sacrifice. Chemiluminescence immunoassay was used for determination of plasma hormone levels, using Beckman Coulter Access-2-immunoassay and reagents (Beckman Coulter, Inc.). Sex was determined from histological examination of gonads. In males, plasma $\mathrm{T}$ levels were positively correlated with temperature (rho $=0.67, \mathrm{P}<0.001$ ). 


\section{A.Y.A. ALKINDI}

However, plasma $E_{2}$ levels were negatively correlated but not strongly with temperature (rho $=-0.396, \mathrm{P}<0.05$ ) and there was a weak correlation between plasma LH levels and temperatures (rho $=0.38, \mathrm{P}<0.05$ ). Also in the males, there was no correlation between temperature and either plasma Pro or $\mathrm{T}_{4}$ levels. In females, there was no correlation between temperature and any of the hormones. In addition, there was no significant difference in plasma concentrations of $\mathrm{T}$, Pro, $\mathrm{LH}$ or $\mathrm{T}_{4}$ between sexes. However, plasma $E_{2}$ concentration was significantly higher in males $(\mathrm{P}<0.05)$. FSH was undetectable in plasma from both sexes. The significance of these findings will be discussed.

KEYWORDS: Circulating hormone, hatchilings, green turtle.

\section{Introduction}

$\mathbf{I}_{\mathrm{c} b \sin }^{\mathrm{n}}$

many reptiles including turtles, sex determination depends on incubation temperature. In chelonian embryos with temperature-dependent sex determination (TSD), the thermosensitive period (TSP) takes place in the middle third period of incubation (Yntema and Mrosovsky, 1982; Wibbels et al. 1991, a, b; Desvages et al. 1993).

In the Olive ridley (Lepidochelys olivacea) TSP was about 7 days (day 20-27 of the incubation period) at a male or female promoting temperature (Merchant-Larios et al. 1997). The rate of gonadal growth was faster at female promoting temperature than at male promoting temperature. During the critical stages of TSP, there is a rapid differentiation in the steroidogenic tissues as well as differential expression of steroidogenic enzymes (Thomas et al. 1992; Fleming et al. 1999; Rhen et al. 1999).

Moreover, sex steroid hormones and particularly estrogens are essential in controlling sex determination (Crews et al. 1994; Crews, 1996; Lance, 1997; Wibbels et al. 1998). Administration of exogenous estrogens to the red-eared slider turtle (Trachemys scripta) was capable of changing males to females during TSP despite the temperature effect (Crews et al. 1991). Administration of exogenous aromatase inhibitor, the enzyme that is responsible for estrogen biosynthesis, can override the female-promoting incubation temperature that resulted in male hatchlings (Crews et al. 1994; Wibbels and Crews, 1994).

Rhen et al. (1999) reported that incubation temperature could influence sex steroid levels 6 weeks after hatching in the red-eared slider turtle. Temperature may be transduced into steroid signals for controlling gonadal differentiation. Steroidogenic factor 1 (SF-1) regulated steroidogenic enzymes expressed during TSP in red-eared slider turtle (Fleming et al. 1999; Fleming and Crews, 2001).

This report represents a preliminary investigation on monitoring plasma sex steroids, gonadotropins and thyroxine in the green turtle hatchlings immediately after emergence. Such findings are valuable in understanding the physiological and hormonal status in the green turtles, and provide important preliminary information for future conservation programs of these animals at Ras Al-Hadd Reserve, Oman.

\section{Methods}

\subsection{Study Area}

Ras Al-Hadd Reserve (between $22^{\circ} 32 \mathrm{~N}$ and $59^{\circ} 45 \mathrm{E}$ and $22^{\circ} 14 \mathrm{~N}$ and $59^{\circ} 48 \mathrm{E}$ ) is a $45 \mathrm{~km}$ coastal strip on the Gulf of Oman and the Arabian Sea with over 20 major sandy beaches that extend from Al-Jarama Bay to Ras Ar Ruays. The first $4 \mathrm{~km}$ in the northern section of the Reserve is located on the Gulf of Oman while the rest (approx. 41 km.) is located on the Arabian Sea. 


\section{CIRCULATING HORMONE LEVELS IN HATCHINGS OF GREEN TURTLE}

\subsection{Egg Collection}

Eggs were collected randomly within $1 \mathrm{~km}$ area from 5 different nests immediately after oviposition from Ras Al Hadd Reserve-Oman in January and May 2003. Each nest was excavated and eggs were taken out. The eggs were then transported in plastic buckets with damp sand from Ras AlHadd to the Department of Biology at Sultan Qaboos University (SQU) and placed in the incubators about $16 \mathrm{hr}$ after oviposition.

\subsection{Method of Incubation}

Each egg was incubated singly in $600 \mathrm{ml}$ plastic container according to the method of Mrosovsky (1988), with some modifications. Each container had a plastic cover $10 \mathrm{~cm}$ in diameter. The upper part of the container was punched (eight holes in each container, $2.5 \mathrm{~mm}$ in diameter). Each egg was placed at the center of the container on top of sponge foam surrounded by vermiculite. In each container, $65 \mathrm{ml}$ of distilled water was added to moisten the foam. Additional $65 \mathrm{ml}$ of distilled water was added to the vermiculite on day 20 of incubation.

The eggs were placed in Precision Scientific incubators (Thermo Forma, Marietta, OH, USA) adjusted to run at different temperatures. Eggs incubated at $30-31^{\circ} \mathrm{C}$ produced females while eggs incubated at $26-27^{\circ} \mathrm{C}$ produced males. Uncovered containers containing distilled water were placed at the bottom of the incubators in order to provide humidity for the eggs.

Two mercury thermometers with $0.1^{\circ} \mathrm{C}$ graduation were placed inside the incubators at the center of each shelf to ascertain temperature accuracy. Daily temperature readings were quickly taken when the incubator was opened. On the outside of the incubator a temperature gauge was checked to make sure that there was no significant fluctuation between daily temperature readings.

\subsection{Fixation and Tissue Processing}

Hatchlings were sacrificed and the gonads were dissected along with the adjacent kidneys. They were fixed in $10 \%$ buffer formaline and then processed for light microscope according to the method of Mrosovsky, (1988).

\subsection{Blood Collection}

Blood samples were collected from the hatchlings approximately 24h after hatching. The hatchlings were sacrificed and plasma was obtained from the blood samples.

\subsection{Determination of Plasma Steroid Concentrations}

Chemiluminescence immunoassay was used for the determination of plasma steroids, FSH, LH and $\mathrm{T}_{4}$ levels using a Beckman Coulter Access 2 immunoassay system and reagents. (Beckman Coulter, Inc., USA). The technique detects the emission of light due to the occurrence of a chemical reaction. It involves the release of energy in the form of photons as the electrons move from the excited state to the ground state.

\subsection{Statistical Methods}

The non-parametric Mann-Whitney $U$ test was used to compare the differences of hormone levels between the sexes while Spearman correlation was used to test the correlation between the hormones values. $(\mathrm{P}<0.05)$ was considered significant. 


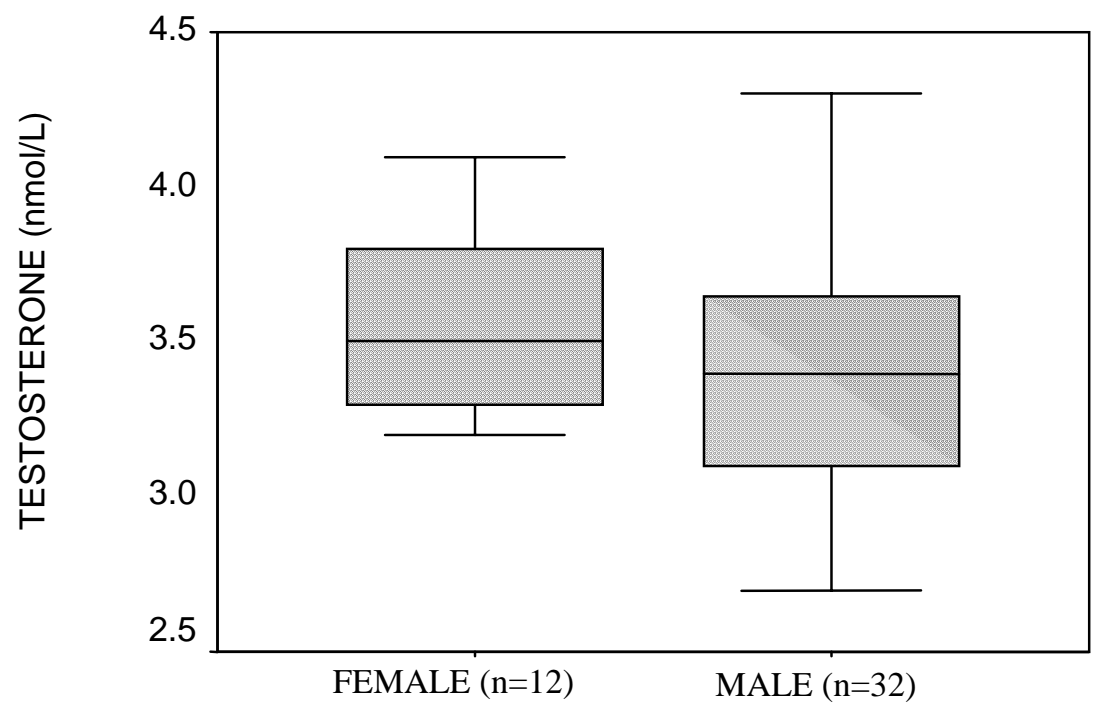

Figure 1. Box plots of plasma testosterone levels in hatchlings of the green turtles Chelonia mydas incubated in laboratory under constant temperature. Boxes represent the middle $50 \%$ of the observations. Horizontal lines inside the boxes represent the median. Observations beyond the vertical lines are outliers.

Table 1. Plasma hormone levels and the incubation temperature of hatchlings - green turtles, Chelonia mydas. (*Significant at $\mathrm{P}<0.05$ )

\begin{tabular}{|c|c|c|c|c|}
\hline Hormone values & Sex and number & Mean $\pm S E M$ & \multicolumn{2}{|c|}{ Incubation temperature ${ }^{\circ} \mathrm{C}$} \\
\hline $\begin{array}{l}\text { Testosterone } \\
(\mathrm{nmol} / \mathrm{L})\end{array}$ & $\begin{array}{l}\mathrm{F}=12 \\
\mathrm{M}=32\end{array}$ & $\begin{array}{l}3.57 \pm 0.081 \\
3.41 \pm 0.069 \\
\end{array}$ & $\begin{array}{l}F=16 \\
M=39\end{array}$ & $\begin{array}{r}3015 \pm 0.28 \\
2719 \pm 0.18 \\
\end{array}$ \\
\hline $\begin{array}{l}\text { Estradiol } \\
\text { (nmol/L) }\end{array}$ & $\begin{array}{l}F=11 \\
M=36\end{array}$ & $\begin{array}{l}0.18 \pm 0.03 \\
0.27 \pm \\
0.02 *\end{array}$ & & “ \\
\hline $\begin{array}{l}\text { Progesterone } \\
(\mathrm{nmol} / \mathrm{L})\end{array}$ & $\begin{array}{l}F=12 \\
M=34\end{array}$ & $\begin{array}{l}11.16 \pm 1.77 \\
10.08 \pm 0.88\end{array}$ & & “ \\
\hline $\begin{array}{l}\text { Luteinizing hormone } \\
\text { (IU/L) }\end{array}$ & $\begin{array}{l}\mathrm{F}=11 \\
\mathrm{M}=30\end{array}$ & $\begin{array}{l}0.15 \pm 0.04 \\
0.27 \pm 0.05\end{array}$ & & “ \\
\hline $\begin{array}{l}\text { Thyroxine } \\
\text { (pmol/L) }\end{array}$ & $\begin{aligned} F & =9 \\
M & =16\end{aligned}$ & $\begin{array}{l}45.20 \pm 3.16 \\
52.90 \pm 4.27\end{array}$ & & “ \\
\hline
\end{tabular}

\section{Results}

$\mathrm{P}, \mathrm{T}, \mathrm{LH}$ and $\mathrm{T}_{4}$ plasma values were not significantly different between sexes (Figs. 1-5). However, $E_{2}$ levels were significantly higher in males over females $(\mathrm{P}<0.05)$ (Fig. 2). FSH levels were undetectable in both sexes. Hormone values are reported in Table 1. 


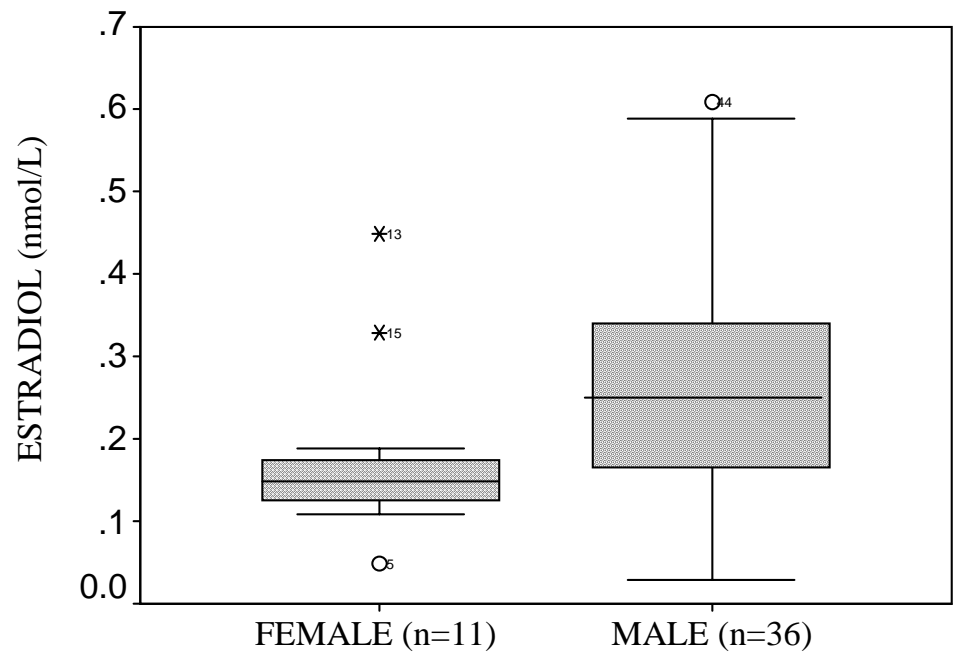

Figure 2. Box plots of plasma estradiol levels in hatchlings of the green turtles Chelonia mydas incubated in laboratory under constant temperature. See Fig 1 for explanation.

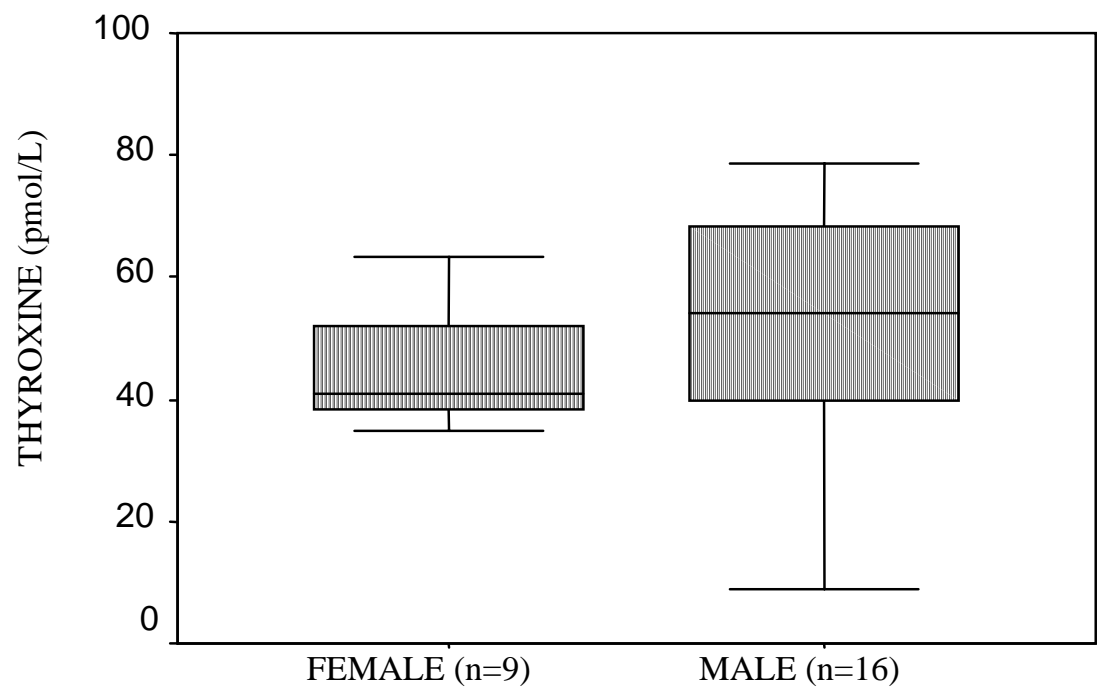

Figure 3. Boxplots of plasma thyroxine levels in hatchlings of the green turtles Chelonia mydas incubated in laboratory under constant temperature. See Fig 1 for explanation.

In the female hatchlings, there was no correlation between plasma levels of $E_{2}$, Pro, T, LH and $\mathrm{T}_{4}$, and the incubation temperature. There was also no correlation between the hormone levels. In male hatchlings, incubation temperature was positively correlated with plasma $\mathrm{T}$ levels (rho $=0.67$, $\mathrm{P}=<0.01$ ) but there was a weak negative correlation with plasma $\mathrm{E}_{2}$ levels (rho $=-0.4, \mathrm{P}=<0.05$ ). As the incubation temperature increased there was a decrease in plasma $\mathrm{E}_{2}$ levels. Also, there was a weak 


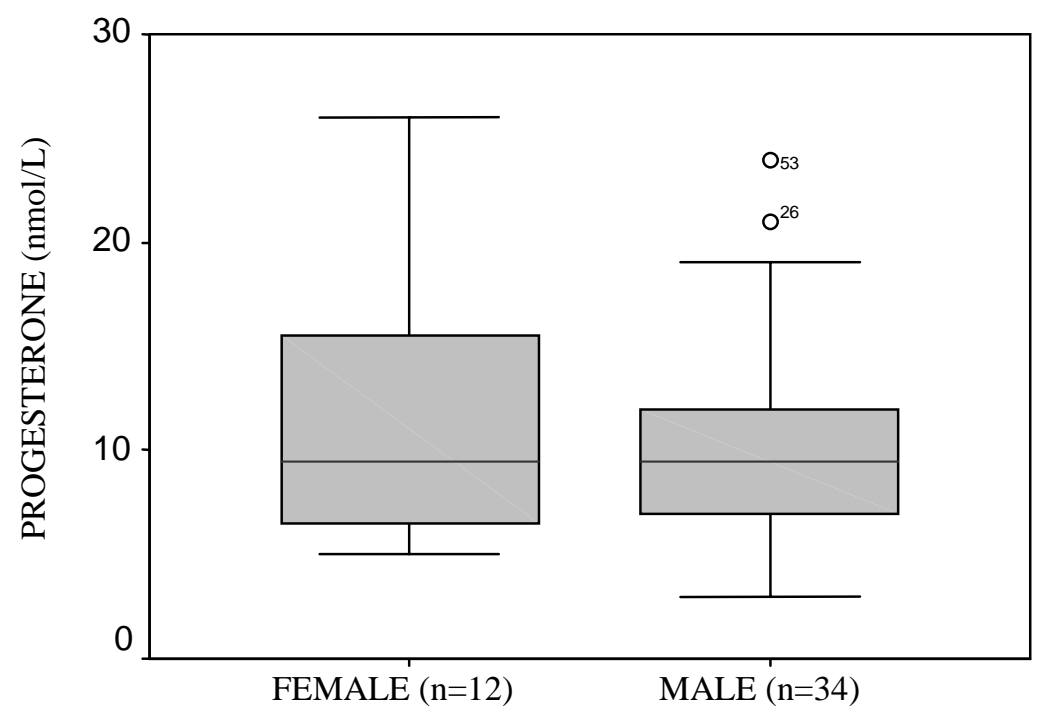

Figure 4. Boxplots of plasma progesterone levels in hatchlings of the green turtles Chelonia mydas incubated in laboratory under constant temperature. See Fig 1 for explanation.

correlation between incubation temperature and plasma LH concentration (rho $=0.380, \mathrm{P}<0.05$ ). There was no correlation between incubation temperature and plasma $\mathrm{P}$, and $\mathrm{T}_{4}$ levels.

Light microscopic studies indicated that in the female the gonadal medulla was degenerative while the cortex was well developed with the appearance of the primary follicles.

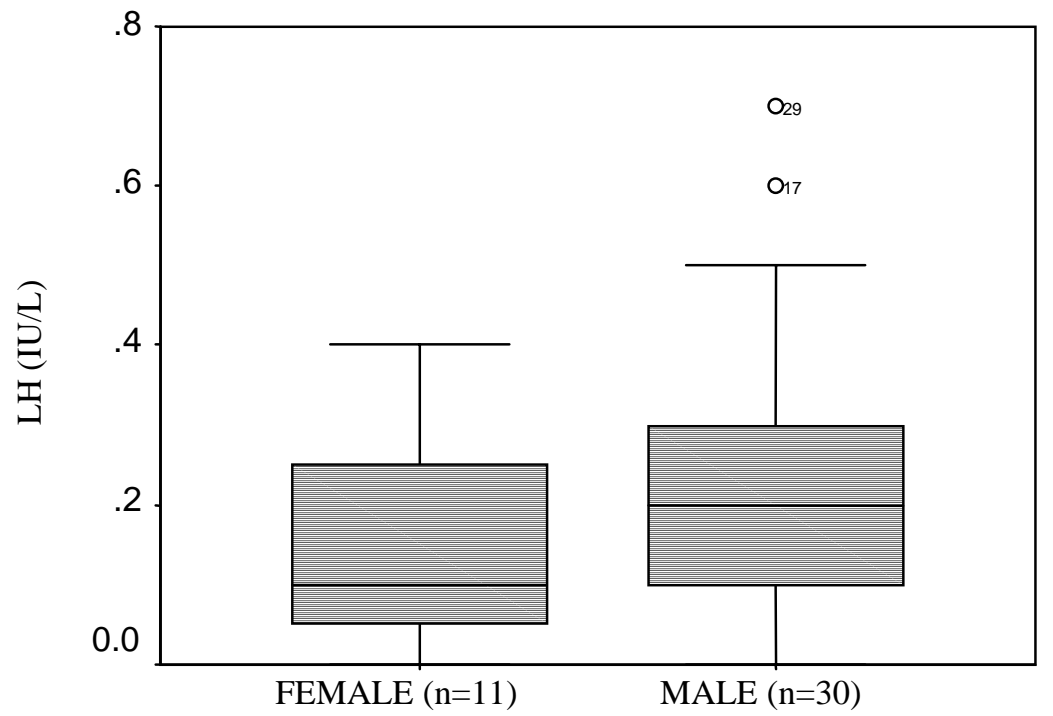

Figure 5. Boxplots of plasma LH levels in hatchlings of the green turtles Chelonia mydas incubated in laboratory under constant temperature. See Fig 1 for explanation. 


\section{Discussion}

Plasma levels of steroids ( $\mathrm{E}_{2}$, Pro and $\mathrm{T}$ ) gonadotropins (FSH and $\left.\mathrm{LH}\right)$ and thyroxine $\left(\mathrm{T}_{4}\right)$ were analyzed shortly after hatching in relation to the incubation temperature in the green turtles collected from Ras Al-Hadd, Oman.

The results indicate that there is no clear pattern in the hormonal levels of the male and female hatchlings $24 \mathrm{hr}$ after emergence. The lack of specific differences in hormone values may indicate that these hatchlings are still in their transitional stage of gonadal development and may take sometime before any conclusive difference in hormonal levels can take place. On the other hand, the histological sex differences clearly show that in the males, the gonadal tissue cortex is degenerative while the medulla is well developed with distinct appearance of the seminiferous tubules. In the female gonadal tissue the medulla is degenerative while the cortex is well developed with the appearance of the primary follicles.

The values of plasma hormone levels in the females did not show any correlation with the incubation temperature. However, in males the incubation temperature was positively correlated with $\mathrm{T}$ and $\mathrm{LH}$ levels but negatively correlated with $\mathrm{E}_{2}$. Also, Pro, $\mathrm{T}_{4}$ levels were not correlated with the incubation temperature. FSH levels were not detected in both sexes. There was no significant difference in hormone levels between the sexes except $E_{2}$ levels, which were higher in males over the females.

These results indicate that there was no conclusive evidence that the incubation temperature had any lasting influence on steroidogenesis immediately after emergence in the green turtles.

Rhen et al. (1999) reported that the incubation temperature in the red-eared slider turtles Trachemys scripta, a species with TSD, had lasting effects on the sex-steroid levels even six weeks after hatching. Plasma thyroxine levels did not show any correlation with the incubation temperature and there was no significant difference between the sexes.

In the snapping turtle (Chelydra serpentina) plasma $\mathrm{T}_{4}$ levels from hatchlings emerging from eggs incubated at $21.5^{\circ} \mathrm{C}$ average $220 \%$ that of turtles emerging from eggs incubated at $30.5^{\circ} \mathrm{C}$ (O’Steen and Janzen, 1999). However, O’Steen and Janzen, (1999) added triiodothyronine to the eggs during mid-incubation and that may have altered the natural values of $\mathrm{T}_{4}$ in the embryo. In the present study carried out in both sexes, $\mathrm{T}_{4}$ levels did not show any correlation with the incubation temperature.

A comprehensive investigation on the relationship between stages of TSP and the steroidogenic pathways must be investigated before drawing any conclusion on the effects of incubation temperature on the hormone levels in the hatchlings of a TSD species like the green turtles.

\section{Acknowledgement}

The author would like to acknowledge the technical assistance provided by Mr. Matar Al-Maani and Mr. Sultan Al- Siyabi during the course of this study.

\section{References}

CREWS, D., BULL, J.J and WIBBELS, T. 1991. Estrogen and sex reversal in turtles: A dosedependent phenomenon. Gen. Comp.Endocrinol. 81: 357-364.

CREWS, D. 1996. Temperature-dependent sex determination: the interplay of steroid hormones and temperature. Zool. Sci. 13: 1-13.

CREWS, D., BULL, J.J., SKIPPER, J.K., TOUSIGNANT, A. and WIBBELS, T. 1994. Temperaturedependent sex determination in reptiles: proximate mechanisms, Ultimate outcomes, and practical applications. Dev. Genet. 15: 297-312. 
DESVAGES, G., GIRONDOT, M. and PIEAU, C. 1993. Sensitive stages for the effects of temperature on gonadal aromatase activity in embryos of the marine turtle Dermochelys coriacea. Gen. Comp. Endocrinol. 92: 54-61.

FLEMING, A., and CREWS, D. 2001. Estradiol and incubation temperature modulate regulation of steroidogenic Factor 1 in the developing gonad of the red-eared slider turtle. Endocrinology. 142: $1403-1411$.

FLEMING, A., WIBBELS, T., SKIPPER, J.K and CREWS, D. 1999. Developmental expression of steroidogenic factor 1 in a turtle with temperature-dependent sex determination. Gen. Comp. Endocrinol. 116: 336-346.

LANCE, V. A. 1997. Sex determination in reptiles: an update. Am. Zool. 37: 504-513.

MERCHANT-LARIOS, H., RUIZ-RAMIREZ, S., MORENO-MENDOZA, N. and MARMOLEJOVALENCIA, A. 1997. Correlation among thermosensitive period, estradiol response, and gonad differentiation in the sea turtle Lepidochelys olivacea. Gen. Comp. Endocrinol. 107: 373-385.

MROSOVSKY, N. 1988. Pivotal temperatures for loggerhead turtles (Caretta caretta) from northern and southern nesting beaches. Can. J. Zool. 66: 661-669.

O’STEEN, S. and JANZEN, F.J. 1999. Embryonic temperature affects metabolic compensation and thyroid hormones in hatching snapping turtles. Physiol. Biochem. Zool. 72(5): 520-533.

RHEN, T., WILLINGHAM, E., SAKATA, J.T. and CREWS, D. 1999. Incubation temperature influences sex-steroid levels in juvenile red-eared slider turtles, Trachemys scripta, a species with temperature-dependent sex determination. Biology of Reproduction. 61: 1275-1280.

THOMAS, E. O.,LIGHT, P., WIBBELS, T. and CREWS, D. 1992. Hydroxysteroid dehydrogenase activity associated with sexual differentiation in embryos of the turtle Trachemys scripta. Biology of Reproduction. 46: 140-145.

WIBBLES, T. and CREWS, D. 1994. Putative aromatase inhibitor induces male sex determination in a female unisexual lizard and in a turtle with TSD. J. Endocrinol. 141:295-299.

WIBBELS, T., BULL, J.J. and CREWS, D. 1991(a). Synergism of temperature and estradiol: a common pathway in sex determination. J. Exp. Zool. 260:130-134.

WIBBELS, T., BULL, J.J. and CREWS, D. 1991(b). Chronology and morphology of temperaturedependent sex determination. J. Exp. Zool. 260: 71-381.

WIBBELS, T., COWAN, J. and LEBOEUF, R. 1998. Temperature-dependent sex determination in the red-eared slider turtle, Trachemys scripta. J. Exp. Zool. 281: 409-416.

YNTEMA, C.L., and MROSOVSKY, N. 1982. Critical periods and pivotal temperatures for sexual differentiation in loggerhead sea turtles. Can. J. Zool. 60: 1012-1016.

Received 17 October 2004

Accepted 10 June 2005 